Check for updates

Cite this: RSC Adv., 2019, 9, 31911

Received 24th July 2019

Accepted 29th September 2019

DOI: 10.1039/c9ra05722f

rsc.li/rsc-advances

\section{Changes in magnetic order through two consecutive dehydration steps of metal- phosphonate diamond chains $\uparrow$}

\author{
Yan-Hui Su, $\dot{t}^{a}$ Jia-Ge Jia, $\dot{t}^{\mathrm{a}}$ Xin-Da Huang, ${ }^{a}$ Jian-Shen Feng, ${ }^{a}$ Song-Song Bao, ${ }^{a}$ \\ Min Ren, ${ }^{a}$ Mohamedally Kurmoo ${ }^{b}$ and Li-Min Zheng (iD *a
}

Hydrothermal reactions of the multitopic ligand 1-hydroxy-1-(piperidin-4-yl)methylidenebisphosphonic acid $\left(\mathrm{hpdpH}_{4}\right)$ with cobalt or nickel sulfates afforded two new isostructural metal phosphonates, $\mathrm{M}_{3}^{\prime \prime}(\mathrm{hpdpH})_{2}\left(\mathrm{H}_{2} \mathrm{O}\right)_{6} \cdot 4 \mathrm{H}_{2} \mathrm{O}\left[\mathrm{M}=\mathrm{Co}\left(\mathrm{Co}-10 \mathrm{H}_{2} \mathrm{O}\right), \mathrm{Ni}\left(\mathrm{Ni}-10 \mathrm{H}_{2} \mathrm{O}\right)\right]$. Their structures consist of parallel diamond chains of three $\mathrm{MO}_{6}$ octahedra bridged by the $\mathrm{PO}_{3} \mathrm{C}$ tetrahedra. Six of the seven oxygen atoms of the ligand are involved in coordination; for two ligands that amounts to 12 bonds for $3 \mathrm{MO}_{6}$ and the remaining six are occupied by terminal water molecules. In addition, four water molecules sit in between the chains providing $\mathrm{H}$-bonds to the formation of a 3D-net. Thermal analyses show identical two-step dehydration processes involving first the departure of six water molecules followed by the remaining four. A detailed study of the ac- and dc-magnetization as a function of temperature, field and frequency reveals associated drastic changes. The virgin form $\mathrm{Co}-10 \mathrm{H}_{2} \mathrm{O}$ is a paramagnet while its partial dehydrated form Co- $4 \mathrm{H}_{2} \mathrm{O}$ is an antiferromagnet displaying canting below $T_{\mathrm{N}}=4.7 \mathrm{~K}$ and the fully dehydrated form $\mathrm{Co}$ is a ferrimagnet $\left(T_{\mathrm{C}}=12 \mathrm{~K}\right)$. Ni-10 $\mathrm{H}_{2} \mathrm{O}$ and $\mathrm{Ni}-4 \mathrm{H}_{2} \mathrm{O}$ exhibit long-range ordered antiferromagnetism ( $T_{\mathrm{N}}=2.7$ and $4.0 \mathrm{~K}$, respectively) and also become ferrimagnets $\left(T_{\mathrm{C}}=9.4 \mathrm{~K}\right)$ when fully dehydrated to Ni. The dehydrated samples can be fully rehydrated with the complete recovery of both the structures and magnetic properties.

\section{Introduction}

The chemistry of metal phosphonates has been receiving an increasing amount of attention because of their potential application in catalysis, ion-exchange, and gas adsorption, as well as having optical, magnetic and proton conducting properties. ${ }^{1-3}$ The derivatives of methylenediphosphonates $\left(\mathrm{H}_{2} \mathrm{O}_{3}\right.$ $\left.\mathrm{PC}\left(\mathrm{R}^{\prime}\right)\left(\mathrm{R}^{\prime \prime}\right) \mathrm{PO}_{3} \mathrm{H}_{2}\right)$ are capable of binding metal ions in different coordination modes, thus resulting in metal phosphonates with versatile architectures and interesting associated physical properties. ${ }^{4}$ For example, a series of metal diphosphonate compounds based on 1-hydroxylidene-diphosphonate $\left[\mathrm{hedpH}_{4}\right.$, $\left.\mathrm{CH}_{3} \mathrm{C}(\mathrm{OH})\left(\mathrm{PO}_{3} \mathrm{H}_{2}\right)_{2}\right]$ have been prepared which show structures ranging from $0 \mathrm{D}$ mononuclear species or clusters, 1D chains, 2D layers to 3D frameworks., ${ }^{5,6}$ The modification of the organic

\footnotetext{
${ }^{a}$ State Key Laboratory of Coordination Chemistry, School of Chemistry and Chemical Engineering, Collaborative Innovation Center of Advanced Microstructures, Nanjing University, Nanjing 210023, P. R. China.E-mail: lmzheng@nju.edu.cn

${ }^{b}$ Université de Strasbourg, Institut de Chimie de Strasbourg, CNRS-UMR7177, 4 rue Blaise Pascal, Strasbourg Cedex 67070, France

$\dagger$ Electronic supplementary information (ESI) available: TGA, IR spectra, and additional magnetic property. CCDC 1901442 (Co-10H $\mathbf{2}$ ) and 1920728 $\left(\mathbf{N i - 1 0 H _ { 2 }} \mathbf{O}\right)$. For ESI and crystallographic data in CIF or other electronic format see DOI: $10.1039 / \mathrm{c} 9 \mathrm{ra05722f}$

\$ These two authors are equal contributors to this work.
}

groups may easily alter the structures and, consequently, their physical properties. Thus when the methyl group in hedpH $\mathrm{H}_{4}$ is replaced by pyridyl-, imidazole- or other groups, new types of chain or layer architectures can be obtained showing interesting magnetic or optical properties. ${ }^{7-9}$

On the other hand, cobalt compounds showing drastic magnetic changes to external stimuli are of great interest as candidates for switchable molecular magnets and as potential sensors. Such changes can be induced by temperature, ${ }^{10}$ light, ${ }^{11}$ redox, ${ }^{12}$ desorption/adsorption of guest molecules or coordinated water molecules. ${ }^{13}$ Although dehydration induced magnetic changes render ground-state switching in a number of coordination systems, ${ }^{14}$ it has rarely been described for cobalt $^{15,16}$ or nicke ${ }^{17}$ phosphonate systems. Examples include a layer compound $\mathrm{Co}(2-\mathrm{pmp})\left(\mathrm{H}_{2} \mathrm{O}\right)_{2} \quad\left(2-\mathrm{pmpH}_{2}=\right.$ 2-pyridylmethylphosphonic acid) with tuneable metamagnetic behaviour, ${ }^{15}$ and $\left[\mathrm{CoLa}(\right.$ notp $\left.)\left(\mathrm{H}_{2} \mathrm{O}\right)_{4}\right] \cdot n \mathrm{H}_{2} \mathrm{O}\left[\mathrm{notpH}_{6}=1,4,7-\right.$ triazacyclononane-1,4,7-triyl-tris(methylenephosphonic acid)] exhibiting oxidation state change of cobalt ion during the dehydration process. ${ }^{16}$ Furthermore, only a few examples are known to change the magnetic ground state upon desolvation and in general, rarely in two consecutive desolvation processes. ${ }^{14}$

In this paper, we report two new metal phosphonates based on 1-hydroxy-1-(piperidin-4-yl)methylidenebisphosphonic acid 
$\left[\left(3-\mathrm{C}_{5} \mathrm{H}_{10} \mathrm{~N}\right) \mathrm{C}(\mathrm{OH})\left(\mathrm{PO}_{3} \mathrm{H}_{2}\right)_{2}, \mathrm{hpdpH}_{4}\right]$ (Fig. 1a) using two divalent first row transition metals (Co and $\mathrm{Ni}$ ) for their different magnetic anisotropies, namely, $\mathrm{Co}_{3}(\mathrm{hpdpH})_{2}\left(\mathrm{H}_{2} \mathrm{O}\right)_{6} \cdot 4 \mathrm{H}_{2} \mathrm{O}$ (Co$\left.\mathbf{1 0 H}_{2} \mathrm{O}\right)$ and $\mathrm{Ni}_{3}(\mathrm{hpdpH})_{2}\left(\mathrm{H}_{2} \mathrm{O}\right)_{6} \cdot 4 \mathrm{H}_{2} \mathrm{O}\left(\mathbf{N i - 1 0 \mathbf { H } _ { 2 }} \mathrm{O}\right)$ as a comparison. The $\mathrm{hpdpH}_{4}$ was selected because the amino group in piperidine can not only serve as a potential coordination donor but also be protonated to adjust the overall charge of the phosphonate ligand, thus providing possibilities to construct new architectures of metal diphosphonates. Both compounds show a one-dimensional chain structure. Interestingly, the two compounds can be dehydrated in two-steps, accompanied with distinct magnetic changes going from paramagnet to canted antiferromagnet/antiferromagnet to ferrimagnet. Moreover, the fully dehydrated samples can be rehydrated with the recovery of both the structures and magnetic properties.

\section{Experiment section}

\section{Materials}

1-Hydroxy-1-(piperidin-4-yl)methylidenebisphosphonic acid $\left(\mathrm{hpdpH} \mathrm{H}_{4}\right)$ was prepared according to the literature method. ${ }^{18}$ All the other starting materials were obtained commercially as reagent grade chemicals and used without further purification.

Synthesis of $\mathrm{Co}_{3}(\mathrm{hpdpH})_{2}\left(\mathrm{H}_{2} \mathrm{O}\right)_{6} \cdot \mathbf{4 H}_{2} \mathrm{O} \quad\left(\mathrm{Co}-10 \mathrm{H}_{2} \mathrm{O}\right) . \quad \mathrm{A}$ mixture of $\mathrm{CoSO}_{4} \cdot 7 \mathrm{H}_{2} \mathrm{O}(0.1 \mathrm{mmol}, 0.029 \mathrm{~g}), \mathrm{hpdpH}_{4}(0.1 \mathrm{mmol}$, $0.028 \mathrm{~g})$ and $\mathrm{H}_{2} \mathrm{O}\left(8 \mathrm{~cm}^{3}\right)$, adjusted to $\mathrm{pH}=3.5$ with $1 \mathrm{M} \mathrm{NaOH}$, was kept in a Teflon-lined autoclave $\left(25 \mathrm{~cm}^{3}\right)$ at $140{ }^{\circ} \mathrm{C}$ for $72 \mathrm{~h}$. After cooling the autoclave to room temperature, red block crystals of Co-10W were collected as a monophasic material, judged by powder X-ray diffraction pattern (Fig. S1 $\dagger$ ). Yield: $8.7 \mathrm{mg}$ (30\% based on Co). Elemental analyses calcd for
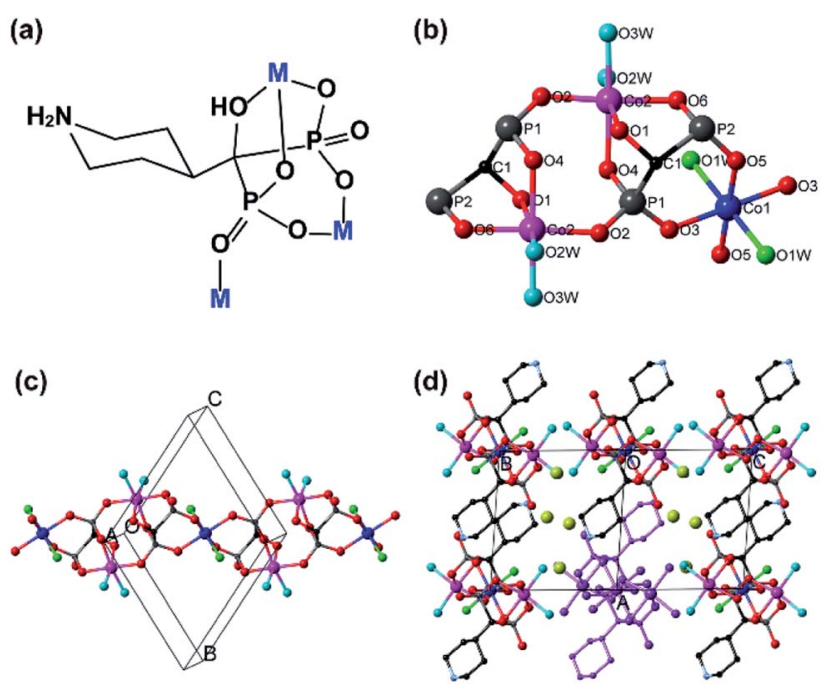

Fig. 1 (a) The coordination mode of $\mathrm{hpdpH}^{3-}$ ligand to three metal centres in compounds $\mathrm{Co}-10 \mathrm{H}_{2} \mathrm{O}$ and $\mathrm{Ni}-10 \mathrm{H}_{2} \mathrm{O}$. Structure represented by $\mathrm{Co}-10 \mathrm{H}_{2} \mathrm{O}$ : (b) a building unit with atomic labelling scheme, (c) fragment of a chain showing the octahedra bridged by $\mathrm{PO}_{3} \mathrm{C}$ tetrahedra, and (d) packing of the chains where one is highlighted in purple. The coordinated water molecules are identified by different colours, cyan in cis-positions of Co2, green in trans-positions of Co1 and yellow for non-coordinated ones of the lattice.
$\mathrm{C}_{12} \mathrm{H}_{44} \mathrm{Co}_{3} \mathrm{~N}_{2} \mathrm{O}_{24} \mathrm{P}_{4}$ (\%): C, 15.99; $\mathrm{H}, 4.92 ; \mathrm{N}, 3.11$. Found: $\mathrm{C}$, 15.43; H, 4.81; N, 2.98. IR (KBr, $\left.\mathrm{cm}^{-1}\right)$ : 3403br, 3067m, 1619s, $1486 \mathrm{w}, 1458 \mathrm{w}, 1384 \mathrm{~m}, 1331 \mathrm{w}, 1274 \mathrm{w}, 1123 \mathrm{vs}, 1094 \mathrm{~s}, 1076 \mathrm{~s}$, $1047 \mathrm{~s}, 1012 \mathrm{~s}, 953 \mathrm{~s}, 925 \mathrm{~m}, 811 \mathrm{~m}, 642 \mathrm{~m}, 574 \mathrm{~s}, 478 \mathrm{w}, 444 \mathrm{~m}$.

Synthesis of $\mathrm{Ni}_{3}(\mathrm{hpdpH})_{2}\left(\mathrm{H}_{2} \mathrm{O}\right)_{6} \cdot \mathbf{4} \mathrm{H}_{2} \mathrm{O}\left(\mathrm{Ni}-10 \mathrm{H}_{2} \mathrm{O}\right)$. This compound was prepared following a similar procedure to that

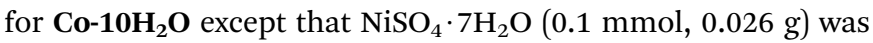
used instead of $\mathrm{CoSO}_{4} \cdot 7 \mathrm{H}_{2} \mathrm{O}$ as the starting material and at $160{ }^{\circ} \mathrm{C}$. Green needle crystals of $\mathbf{N i}-\mathbf{1 0 H}_{2} \mathrm{O}$ were obtained as a monophasic material, judged by powder X-ray diffraction pattern (Fig. S2 $\dagger$ ). Yield: $8.9 \mathrm{mg}$ (30\% based on Ni). Elemental analyses calcd for $\mathrm{C}_{12} \mathrm{H}_{44} \mathrm{Ni}_{3} \mathrm{~N}_{2} \mathrm{O}_{24} \mathrm{P}_{4}$ (\%): C, 16.01; $\mathrm{H}, 4.93 ; \mathrm{N}$, 3.11. Found: C, 16.01 ; H, 5.09; N, 3.04. IR (KBr, $\left.\mathrm{cm}^{-1}\right)$ : $3415 \mathrm{br}$, $3070 \mathrm{~m}, 1619 \mathrm{~s}, 1488 \mathrm{w}, 1461 \mathrm{w}, 1386 \mathrm{~m}, 1326 \mathrm{w}, 1126 \mathrm{~s}, 1105 \mathrm{~s}$, 1081s, 1051s, 1010s, 956m, 925w, 908w, 860m, 815w, $647 \mathrm{~m}$, $574 \mathrm{~s}, 518 \mathrm{~m}, 476 \mathrm{~m}$.

\section{Physical measurements}

The elemental analyses for $\mathrm{C}, \mathrm{H}$ and $\mathrm{N}$ were performed in a PE240C elemental analyzer. The infrared spectra were recorded on a Bruker Tensor 27 spectrometer with ATR mode. Thermal analyses were performed in nitrogen with a heating rate of $5{ }^{\circ} \mathrm{C} \mathrm{min}^{-1}$ on a TGA-DTA V1.1b Inst 2100 instrument. The powder XRD patterns were recorded on a Shimadzu XD-3A $\mathrm{X}$-ray diffractometer. Magnetization were measured using a Quantum Design SQUID VSM magnetometer. The magnetization data were corrected for the diamagnetic contributions of both the sample holder and the compound obtained from Pascal's constants. ${ }^{19}$

\section{X-ray crystallographic studies}

Single crystals of dimensions $0.20 \times 0.15 \times 0.10 \mathrm{~mm}^{3}$ for Co$\mathbf{1 0 H}_{2} \mathrm{O}$ and $0.12 \times 0.10 \times 0.08 \mathrm{~mm}^{3}$ for $\mathbf{N i - 1 0 H _ { 2 }} \mathbf{O}$ were selected for indexing and intensity data collection on a Bruker SMART APEX CCD diffractometer using graphite monochromatized Mo $\mathrm{K} \alpha$ radiation $(\lambda=0.71073 \AA)$ at room temperature. A hemisphere of data was collected in each case in the $\theta$ range 2.275-

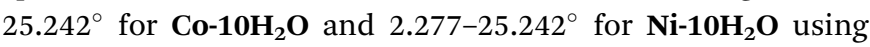
a narrow-frame method with scan widths of $0.30^{\circ}$ in $\omega$ and exposure time of $10 \mathrm{~s}$ per frame. Numbers of observed and unique reflections are 11163 and $2594\left(R_{\text {int }}=0.0139\right)$ for Co$\mathbf{1 0 H}_{2} \mathbf{O}, 7534$ and $2605\left(R_{\text {int }}=0.0255\right)$ for $\mathbf{N i - 1 0 H _ { 2 }} \mathbf{O}$. The data were integrated using the Siemens SAINT program, ${ }^{\mathbf{2}}$ with the intensities corrected for Lorentz factor, polarization, air absorption, and absorption due to variation in the path length through the detector faceplate. Absorption corrections were applied. The structures were solved by direct methods and refined on $F^{2}$ by full matrix least squares using SHELXTL. ${ }^{21}$ All non-hydrogen atoms were located from the Fourier maps and refined with anisotropic thermal parameters. All the hydrogen atoms not located from the Fourier maps were set at calculated positions and refined with isotropic parameters related to the non-hydrogen atom to which they are bonded. Crystallographic and refinement details are listed in Table 1 . The selected bond

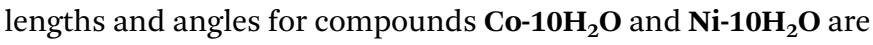
given in Tables $\mathrm{S} 1$ and $\mathrm{S} 2, \uparrow$ respectively. 
Table 1 Crystallographic data for $\mathrm{Co}-10 \mathrm{H}_{2} \mathrm{O}$ and $\mathrm{Ni}-10 \mathrm{H}_{2} \mathrm{O}$

\begin{tabular}{|c|c|c|}
\hline & $\mathrm{Co}-10 \mathrm{H}_{2} \mathrm{O}$ & $\mathrm{Ni}-10 \mathrm{H}_{2} \mathrm{O}$ \\
\hline Empirical formula & $\mathrm{C}_{12} \mathrm{H}_{44} \mathrm{Co}_{3} \mathrm{~N}_{2} \mathrm{O}_{24} \mathrm{P}_{4}$ & $\mathrm{C}_{12} \mathrm{H}_{44} \mathrm{Ni}_{3} \mathrm{~N}_{2} \mathrm{O}_{24} \mathrm{P}_{4}$ \\
\hline$F_{\mathrm{w}}$ & 901.16 & 900.50 \\
\hline Crystal system & Triclinic & Triclinic \\
\hline Space group & $P \overline{1}$ & $P \overline{1}$ \\
\hline$a(\AA)$ & $9.064(4)$ & $9.056(3)$ \\
\hline$b(\AA)$ & $9.536(4)$ & $9.430(3)$ \\
\hline$c(\AA)$ & $9.686(4)$ & $9.605(3)$ \\
\hline$\alpha\left({ }^{\circ}\right)$ & $114.883(6)$ & $114.954(5)$ \\
\hline$\beta\left({ }^{\circ}\right)$ & $97.803(7)$ & $97.790(5)$ \\
\hline$\gamma\left({ }^{\circ}\right)$ & $90.634(6)$ & $90.883(6)$ \\
\hline$V\left(\AA^{3}\right), Z$ & $750.3(5), 1$ & $734.4(4), 1$ \\
\hline$D_{\mathrm{c}}\left(\mathrm{g} \mathrm{cm}^{-3}\right)$ & 1.994 & 2.036 \\
\hline$\mu\left(\mathrm{mm}^{-1}\right)$ & 1.953 & 2.224 \\
\hline$F(000)$ & 463 & 466 \\
\hline$R_{1}^{a}, \mathrm{wR}_{2}^{b}[I>2 \sigma(I)]$ & $0.0374,0.1187$ & $0.0561,0.1141$ \\
\hline$R_{1}{ }^{a}, \mathrm{w}_{2}{ }^{b}$ (all data) & $0.0398,0.1223$ & $0.0767,0.1226$ \\
\hline Goodness-of-fit & 1.005 & 1.001 \\
\hline$(\Delta \rho) \max , \min \left(\mathrm{e} \AA^{-3}\right)$ & $0.58,-0.83$ & $0.86,-0.69$ \\
\hline CCDC number & 1901442 & 1920728 \\
\hline
\end{tabular}

\section{Results and discussion}

\section{Synthesis}

Crystals of $\mathbf{C o -} \mathbf{1 0 H}_{2} \mathrm{O}$ and $\mathbf{N i - 1 0 H _ { 2 }} \mathrm{O}$ were prepared by the reaction of the metal sulfates and $\mathrm{hpdpH}_{4}$ under hydrothermal conditions. The $\mathrm{M}$ : ligand ratio, $\mathrm{pH}$ and reaction temperature could play critical roles in yielding pure phases. $\mathbf{C o - 1 0 \mathbf { H } _ { 2 }} \mathbf{O}$ with good crystal quality was prepared as a pure phase at 140 or $160{ }^{\circ} \mathrm{C}$, pH of 3.0-3.5 and the Co: $\mathrm{hpdpH}_{4}$ molar ratio of $1: 1-2$. At a low $\mathrm{pH}(<3.0)$, only clear solution was obtained. At moderate $\mathrm{pH}$ (5-7), powder materials were obtained which showed the same PXRD patterns with that of $\mathbf{C o -} \mathbf{1 0 H}_{2} \mathbf{O}$ (Fig. S3 $\dagger$ ). For Ni$\mathbf{1 0 H}_{2} \mathrm{O}$, a pure phase with good crystal quality was obtained at $160{ }^{\circ} \mathrm{C}$ when the $\mathrm{pH}$ ranged between 2.5 and 4.0 and the

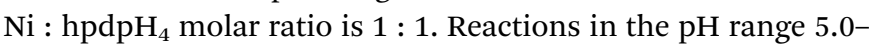
7.0 resulted in crystals of $\mathbf{N i - 1 0 H _ { 2 }} \mathbf{O}$ together with a large amount of powdered materials which had the same PXRD patterns with that of $\mathbf{N i - 1 0 H _ { 2 }} \mathbf{O}$ (Fig. S3 $\dagger$ ). When the $\mathrm{Ni}: \mathrm{hpdpH}_{4}$ molar ratio is lowered to $1: 0.5$, bigger block-shaped crystals of Ni-10H $\mathbf{H}_{2} \mathrm{O}$ can be obtained but in a rather low yield. Notably, although the powder samples obtained at higher $\mathrm{pH}$ show identical PXRD patterns in both cases, the presence of impurities in the powder products cannot be fully excluded. Therefore, only crystals of $\mathbf{M - 1 0 H _ { 2 }} \mathbf{O}$ were selected to be used for further physical measurements.

\section{Description of the structures}

The key feature of the two isostructural compounds differing only in the metals, Co and $\mathrm{Ni}$, is the diamond chain of the metals along the [011] direction of the triclinic cell (Fig. 1 and Table 1). The piperidine alternately points above and below along the chains. The chains are packed parallel to one another forming layers separated by the piperidine and four water of crystallization per formula unit, $\mathrm{M}_{3}{ }^{\mathrm{II}}(\mathrm{hpdpH})_{2}\left(\mathrm{H}_{2} \mathrm{O}\right)_{6} \cdot 4 \mathrm{H}_{2} \mathrm{O}$. The asymmetric unit contains 1.5 metal, 1 ligand and $5 \mathrm{H}_{2} \mathrm{O}$. Thus, the ligand has lost three of its five protons to $\mathrm{hpdpH}^{3-}$. As we anticipated with our design of the ligand, it uses a high number of six of the eight potential coordinating atoms to connect the metal centers. It makes three different modes of coordination: a six-membered chelate M1-O-P-C-P-O-M1, a capping tripod to $\mathrm{M} 2$ through two five-membered chelates involving the alcohol oxygen atom, and a single terminal bond to M2. This leaves one phosphonate oxygen and the nitrogen atoms free from coordination.

The two independent metal ions adopt slightly distorted octahedral geometries where four of their oxygen atoms come from the phosphonates and the other two from coordinated water molecules. The latter are in trans-position for M1 but they are in cis-position for M2. The metal-oxygen bond lengths and angles are all normal for M(II) octahedra (Tables S1 and S2 $\dagger$ ). All the metals within a trimeric unit are connected through $\mathrm{O}-\mathrm{P}-\mathrm{O}$ bridges. The asymmetric triangle is disposed of one M1-M2 (4.883 $\AA$ for $\mathbf{C o - 1 0 H _ { 2 }} \mathbf{O}$ and $4.836 \AA$ for $\mathbf{N i - 1 0 H _ { 2 }} \mathbf{O}$ ) edge consisting of two anti-anti O-P-O, one M1-M2 (6.365 $\AA$ for Co-

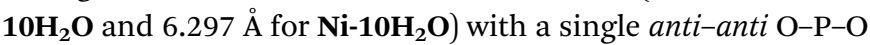

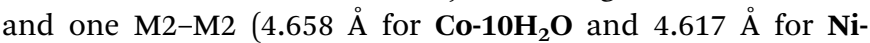
$\mathbf{1 0 H}_{2} \mathrm{O}$ ) with two equivalent syn-anti $\mathrm{O}-\mathrm{P}-\mathrm{O}$. The piperidine nitrogen (N1) is protonated. One interchain $\mathrm{H}$-bond is found between the piperidine nitrogen and phosphonate oxygen (O5)

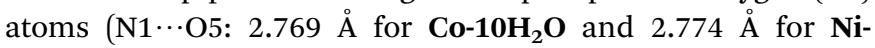
$\mathbf{1 0 H}_{\mathbf{2}} \mathbf{O}$ ), leading to a layer in the ( $\left.\begin{array}{ll}0 & 1-1\end{array}\right)$ plane (Tables S3 and $\mathrm{S} 4 \dagger)$. The interlayer space is occupied by lattice water molecules, extensively $\mathrm{H}$-bonded through the coordinated and lattice water molecules as well as the phosphonate oxygen atoms, leading to a three-dimensional supramolecular network structure (Fig. S4†).

It should be mentioned that the structures of $\mathbf{C o - 1 0 \mathbf { H } _ { 2 }} \mathrm{O}$ and Ni-10H $\mathrm{H}_{2} \mathrm{O}$ are distinguished from that of a related $\mathrm{Cu}_{3}-$ ${ }^{\mathrm{II}}(\mathrm{hpdpH})_{2}\left(\mathrm{H}_{2} \mathrm{O}\right)_{4} \cdot 4 \mathrm{H}_{2} \mathrm{O}$ which includes the same phosphonate ligand. ${ }^{22}$ Although the chemical composition of the copper compound is quite similar, with two less coordinated water molecules, it shows an infinite ladder-like double chain structure in which the $\mathrm{Cu}_{10} \mathrm{O}_{5}$ square pyramids and $\mathrm{Cu} 2 \mathrm{O}_{6}$ octahedra are linked by corner-sharing $\mathrm{PO}_{3} \mathrm{C}$ tetrahedra. The chains are stacked in a perpendicular manner, forming a 3D H-bonded network. Both the intrachain arrangement and the stacking mode of the copper compound are completely different from

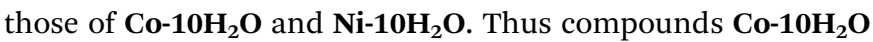
and $\mathbf{N i - 1 0 H _ { 2 }} \mathbf{O}$ provide second example of metal phosphonates based on $\mathrm{hpdpH}_{4}$ ligand with a new structural type.

\section{Thermal analysis}

The two compounds behave in exactly similar way when they are heated at a rate of $5{ }^{\circ} \mathrm{C}$ minute ${ }^{-1}$ under a dry nitrogen atmosphere (Fig. 2). First they lose six water molecules between 80 and $150{ }^{\circ} \mathrm{C}$ with a weight loss of $12.2 \%$ (calcd $12.0 \%$ ) for Co$\mathbf{1 0 H}_{2} \mathrm{O}$ and $\mathbf{1 2 . 0 \%}$ (calcd $12.0 \%$ ) for $\mathbf{N i - 1 0 H _ { 2 }} \mathbf{O}$, which is followed by a second dehydration of four water molecules between 180

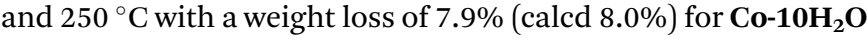




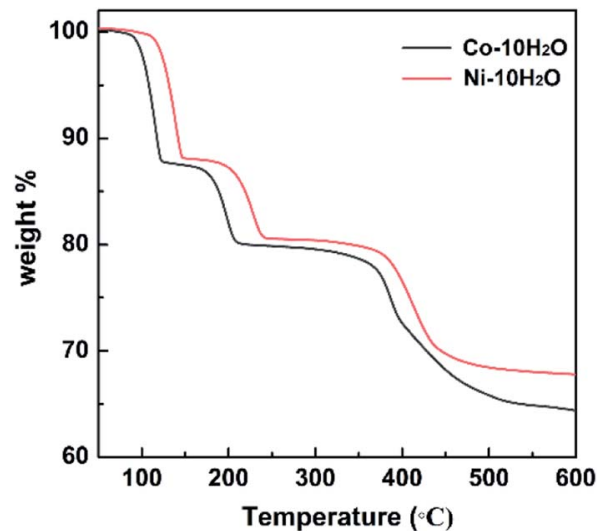

Fig. 2 Thermogravimetric analyses for $\mathrm{Co}-10 \mathrm{H}_{2} \mathrm{O}$ (black) and $\mathrm{Ni}-$ $10 \mathrm{H}_{2} \mathrm{O}$ (red) showing the thermally transformed products.

and $8.0 \%$ (calcd $8.0 \%$ ) for $\mathbf{N i - 1 0 H _ { 2 }} \mathbf{O}$. Interestingly, the nickel compound exhibits ca. $20{ }^{\circ} \mathrm{C}$ higher transformation temperatures than the cobalt one, indicating the stronger binding energies for the former most likely associated with its slightly small ionic radius, as seen in the structural analyses described above (Tables 1, S2 and S3†). A third step follows which corresponds to the decomposition of the piperidine moiety leaving a methyl group. The resulting phase is stable from 500 to $800{ }^{\circ} \mathrm{C}$ before it decomposes to metal-oxide and -phosphate.

Since distinct plateau are observed in the thermogravimetry curves, the partially dehydrated $\mathrm{M}_{3}(\mathrm{hpdpH})_{2}\left(\mathrm{H}_{2} \mathrm{O}\right)_{4}\left(\mathbf{C o}-\mathbf{4} \mathbf{H}_{2} \mathbf{O}\right.$, Ni-4 $\left.\mathbf{H}_{2} \mathrm{O}\right)$ and fully dehydrated $\mathrm{M}_{3}(\mathrm{hpdpH})_{2}(\mathbf{C o}, \mathbf{N i})$ were

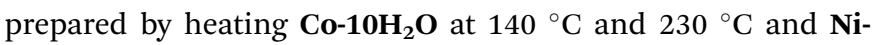
$\mathbf{1 0 H}_{2} \mathrm{O}$ at $170{ }^{\circ} \mathrm{C}$ and $250{ }^{\circ} \mathrm{C}$, respectively, for 20 minutes for other physical property measurements. The number of remaining coordinated water molecules in $\mathbf{C o - 4} \mathbf{H}_{2} \mathrm{O}$ and $\mathbf{N i -}$ $\mathbf{4 H}_{2} \mathrm{O}$ were verified by further TG analyses (Fig. S5 and $\mathrm{S} 6 \dagger$ ).

A strong colour change for the powdered crystals from red to purple to deep blue is observed for $\mathbf{C o - 1 0 \mathbf { H } _ { 2 }} \mathbf{O}$ upon the two-step

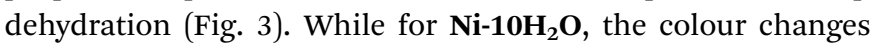
from a light green, yellow to brown. On rehydrating the colour of the powders reverts back but with a little bit less intensity.

The crystallinity of the products of the thermal degradation was checked by powder X-ray diffraction because all attempts using selected crystals indicate they are heavily fragmented with very wide mosaic that hampered structural determination. The PXRD of the partially and fully hydrated phases show

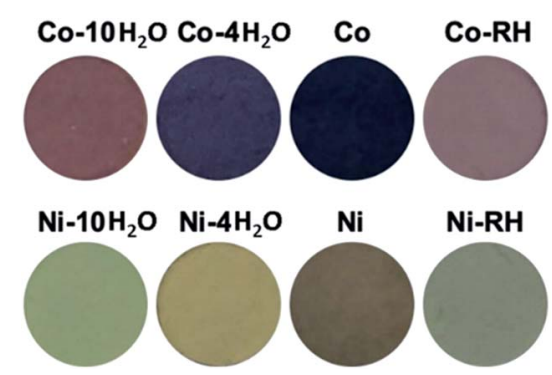

Fig. 3 Photos of the powdered crystals showing the colour changes during the two dehydration processes and after rehydration. reasonable crystallinity and major changes to the unit cells from the virgin crystals (Fig. 4). However, the quality of the data remains low and has prevented further structural analyses. Interestingly, upon rehydration in water vapor at $70{ }^{\circ} \mathrm{C}$ for 3 days the original hydrated forms are reproduced, as confirmed by PXRD and IR measurements (Fig. 4, S7 and S8†).

\section{Magnetic properties}

The magnetic properties of the two compounds have been studied by a series of experiments including (a) the susceptibilities on cooling in an applied field of either 100, 1000 or 2000 Oe, (b) the zero-field-cool (ZFC) and field-cool (FC) magnetizations in an applied field of $10 \mathrm{Oe}$, (c) field dependence of the isothermal magnetization at $2 \mathrm{~K}$ after $\mathrm{ZFC}$ and the acsusceptibilities in an oscillating field of 2 Oe for three different frequencies (73, 333 and $999 \mathrm{~Hz}$ ). These data are shown in Fig. 5 for all the samples as clarified in the appropriate captions. The principal results of the analyses of the data are given in Table 2.

The Curie and Weiss constants for the cobalt phases were estimated from least-square fits of the inverse susceptibility data versus temperature in the range 150 to $300 \mathrm{~K}$ due to the effect of the large spin-orbit coupling. The Curie constants are within the range expected for $\mathrm{Co}(\mathrm{II})$ in the octahedral geometry. The large value is due to both spin and orbital contributions. The Weiss temperatures, a measure of the average magnetic coupling between the nearest neighbors, are negative for the three forms. The values for $\mathbf{C o -} \mathbf{1 0 H}_{2} \mathrm{O}(-14.2 \mathrm{~K})$ and $\mathbf{C o - 4} \mathbf{H}_{2} \mathrm{O}$ $(-15.4 \mathrm{~K})$ are slightly low compared to that expected $(-20 \mathrm{~K})$ for an octahedral $\mathrm{Co}$ (II) whereas that of $\mathrm{Co}(-25.2 \mathrm{~K})$ is slightly high, indicating a stronger antiferromagnetic interaction in the fully dehydrated Co compound.

The Curie and Weiss constants for the nickel phases were estimated from similar fits of the susceptibility data in the wider range 50 to $300 \mathrm{~K}$ due to the weak effect of single-ion anisotropy. ${ }^{23}$ The Curie constants for the three phases correspond to a total of three $S=1 \mathrm{Ni}$ (II) in the octahedral geometry. The Weiss temperatures are negative for the three nickel forms with little changes from one another (Table 2), indicating a dominant antiferromagnetic interactions mediated between the $\mathrm{Ni}$ (II) centers.
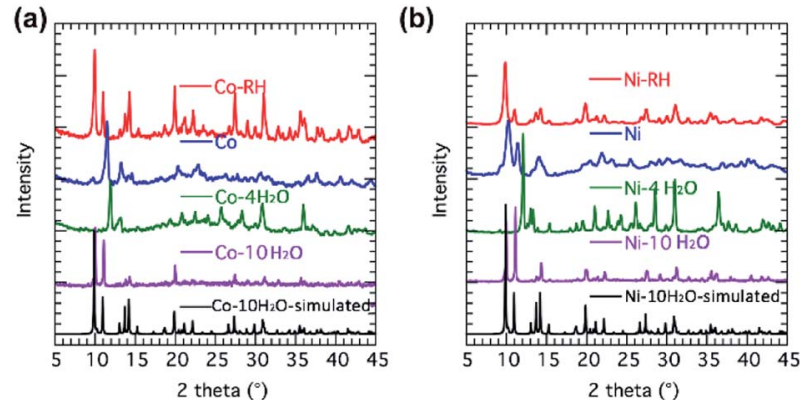

Fig. 4 Powder X-ray diffraction patterns for $\mathrm{Co}-10 \mathrm{H}_{2} \mathrm{O}$ (a) and Ni$10 \mathrm{H}_{2} \mathrm{O}$ (b) and their partially dehydrated $\left(\mathrm{Co}-4 \mathrm{H}_{2} \mathrm{O}\right.$ and $\left.\mathrm{Ni}-4 \mathrm{H}_{2} \mathrm{O}\right)$, fully dehydrated ( $\mathrm{Co}$ and $\mathrm{Ni}$ ) and the rehydrated forms ( $\mathrm{Co}-\mathrm{RH}$ and $\mathrm{Ni}-\mathrm{RH}$ ) compared to those simulated from single crystal structural data. 


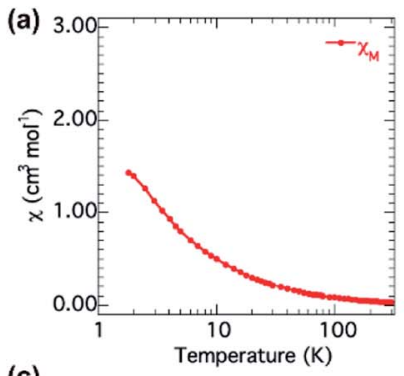

(c)
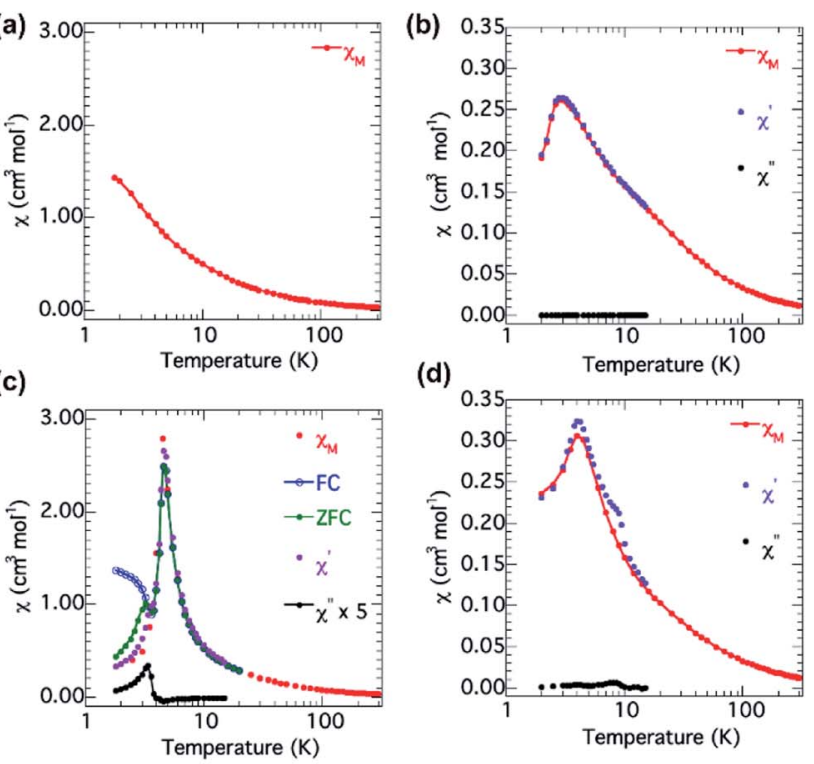

(d)
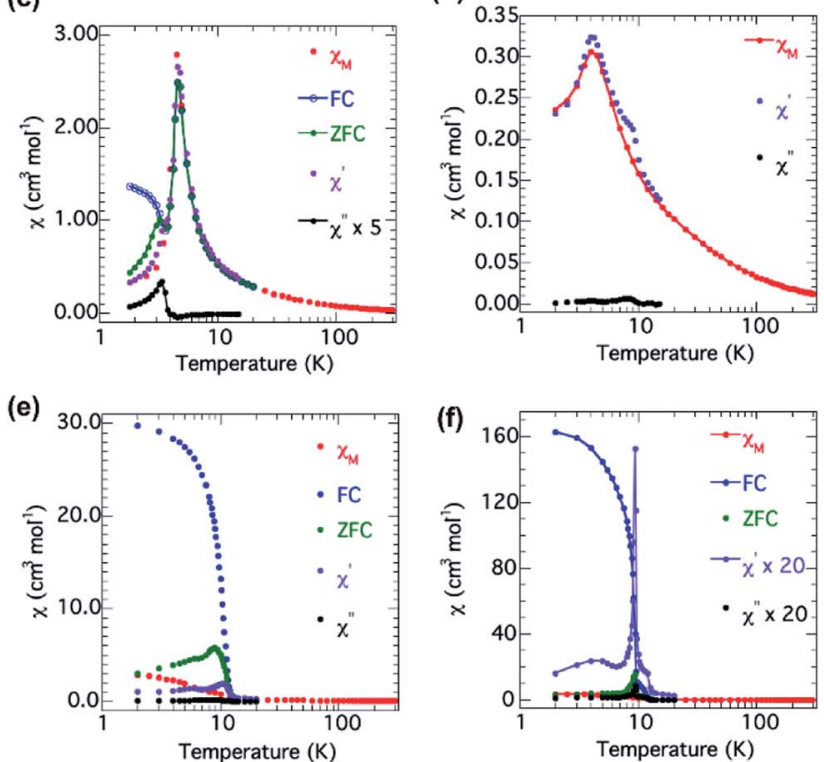

Fig. 5 Temperature dependence of the ac- and dc-magnetic susceptibilities for (a) $\mathrm{Co}-10 \mathrm{H}_{2} \mathrm{O}$, (b) $\mathrm{Ni}-10 \mathrm{H}_{2} \mathrm{O}$, (c) $\mathrm{Co}-4 \mathrm{H}_{2} \mathrm{O}$, (d) $\mathrm{Ni}-$ $4 \mathrm{H}_{2} \mathrm{O}$, (e) Co and (f) $\mathrm{Ni}$.

While the susceptibility data at low temperature for Co$\mathbf{1 0 H}_{2} \mathrm{O}$ are featureless, those for $\mathbf{C o -}-\mathbf{H}_{2} \mathrm{O}$ and Co reveal longrange ordering. For Co-4 $\mathbf{H}_{2} \mathbf{O}$, complementary ZFC-FC data in an applied field of 10 Oe indicate a fully compensated antiferromagnetic state at $T_{\mathrm{N}}=4.7 \mathrm{~K}$, with coincidence of the ZFC and FC data, followed by a canting of the moments below $3.5 \mathrm{~K}$, where a bifurcation is observed. The ac-susceptibilities are

independent of frequency and $\chi^{\prime}$ follows the ZFC dcsusceptibility while $\chi^{\prime \prime}$ only become finite below $3.5 \mathrm{~K}$. This behavior is similar to those observed for $\mathrm{Co}_{2}$ (pyromellitate), $\mathrm{Co}_{2}(\mathrm{OH})_{2}$ (terephthalate) and $\mathrm{Co}_{4}(\mathrm{OH})_{2}(2-\mathrm{pmb})_{2}\left[2-\mathrm{pmbH}_{3}=2\right.$ (phosphonomethyl)benzoic acid]. ${ }^{24}$ For Co both ZFC-FC and acsusceptibilities data show a clear bifurcation associated with the anomaly in $\chi^{\prime \prime}$ at $12 \mathrm{~K}$.

The isothermal magnetizations were measured at $2 \mathrm{~K}$ (Fig. 6). For $\mathbf{C o -} \mathbf{1 0 H}_{2} \mathbf{O}$, a paramagnetic response is observed but it does not reach saturation, which implied some antiferromagnetic coupling between neighboring moment carriers. For $\mathbf{C o - 4} \mathbf{H}_{2} \mathbf{O}$, a complicated behavior emerges with two metamagnetic transformations, one at low field of 30 Oe with a magnetization plateau at $0.15 \mu_{\mathrm{B}}$ and the other at $1.5 \mathrm{kOe}$ to a plateau of $3 \mu_{\mathrm{B}}$, followed by a third gradual increase starting at $25 \mathrm{kOe}$ rising to 6 $\mu_{\mathrm{B}} \cdot{ }^{25}$ The two low-field transformations are hysteretic, 30 Oe and 150 Oe, respectively. They suggest there are two metamagnetic reversals of different energies from an antiferromagnetic ground state. Given the difference, we associate tentatively the first at 30 Oe to that between layers and the second at $1.5 \mathrm{kOe}$ to that between chains. For Co, there is a single hysteresis loop with a coercive field of 850 Oe and a linear dependence with field up to $70 \mathrm{kOe}$. This is interpreted as a ferrimagnetic state. ${ }^{26}$

The nickel series is less complicated. Both Ni-10 $\mathbf{H}_{2} \mathrm{O}$ and Ni$\mathbf{4 H}_{2} \mathrm{O}$ behave in similar fashion with long-range antiferromagnetism at $T_{\mathrm{N}}=2.7$ and $3.8 \mathrm{~K}$, respectively and only the real part of the ac-susceptibilities is active and duplicating the dcsusceptibility. For Ni, all the dc- and ac-susceptibilities have behavior akin that of $\mathbf{C o}$, where the ferrimagnetism sets in at $9.4 \mathrm{~K}$.

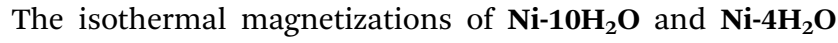
again behave in similar fashion with a metamagnetic critical field of $c a .10 \mathrm{kOe}$ and saturation approaching $2.2 \mu_{\mathrm{B}}$, which would correspond to that of one Ni(II). While the high field may be associated to the spin-flop, the saturation values suggest a ferrimagnetic state results. For $\mathbf{N i}$, a wide hysteresis with a coercive field of $3 \mathrm{kOe}$ is observed and the saturation in $70 \mathrm{kOe}$ is only $2.5 \mu_{\mathrm{B}}$. This is consistent with a ferrimagnetic state. ${ }^{27}$

In the absence of a full structural details of the two less hydrated phases, it is difficult to comment on any structuremagnetic property relationship. However, certain information

Table 2 Results of analyses of the magnetization data ${ }^{a}$

\begin{tabular}{|c|c|c|c|c|c|c|}
\hline & $\begin{array}{l}\text { Curie constant } \\
\left(\mathrm{cm}^{3} \mathrm{~K} \mathrm{~mol}^{-1}\right)\end{array}$ & Weiss constant $(\mathrm{K})$ & Critical temperature (K) & Critical field (Oe) & Coercive field (Oe) & Saturation moment $\left(\mu_{\mathrm{B}}\right)$ \\
\hline $\mathrm{Co}-10 \mathrm{H}_{2} \mathrm{O}$ & $9.62(2)$ & $-14.2(1)$ & - & - & - & 5.9 \\
\hline & & & $T_{\mathrm{CAF}}=3.5$ & $H_{\mathrm{c} 2}=1500$ & 150 & 3 \\
\hline & & & & $H_{\mathrm{c} 2}=25000$ & - & 6 \\
\hline Co & $9.33(2)$ & $-25.2(2)$ & $T_{\mathrm{C}}=12$ & - & 850 & 4.4 \\
\hline $\mathrm{Ni}-4 \mathrm{H}_{2} \mathrm{O}$ & $3.80(1)$ & $-16.7(4)$ & $T_{\mathrm{N}}=4.0$ & $H_{\mathrm{c}}=10000$ & - & 2.1 \\
\hline $\mathrm{Ni}$ & $3.45(1)$ & $-10.8(3)$ & $T_{\mathrm{C}}=9.4$ & - & 3000 & 2.5 \\
\hline Ni-RH & $3.75(1)$ & $-13.0(3)$ & $T_{\mathrm{N}}=\sim 3$ & $H_{\mathrm{c}}=10000$ & - & 2.1 \\
\hline
\end{tabular}


(a)

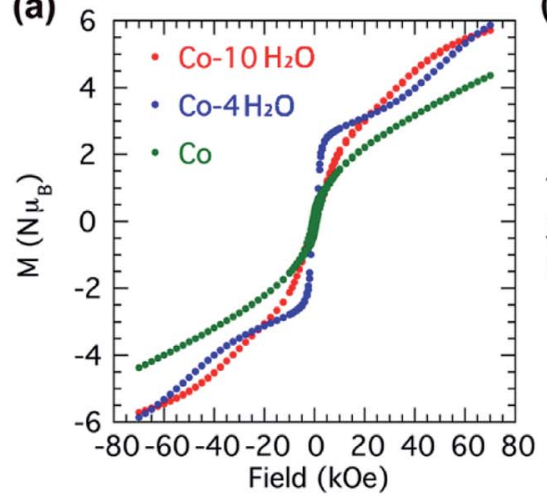

(b)

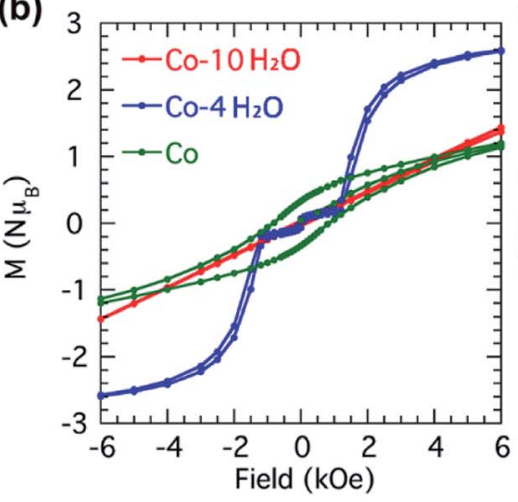

(c)

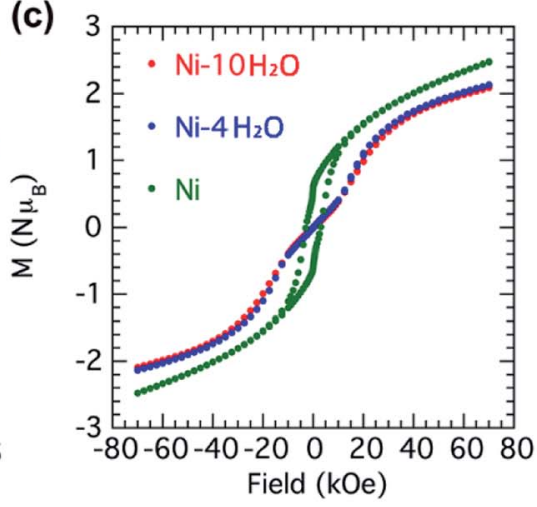

Fig. 6 Isothermal magnetization at $2 \mathrm{~K}$ for (a) $\mathrm{Co}-10 \mathrm{H}_{2} \mathrm{O}, \mathrm{Co}-4 \mathrm{H}_{2} \mathrm{O}$, and $\mathrm{Co}$ in the field of -70 to $70 \mathrm{kOe} ;(\mathrm{b}) \mathrm{Co}-10 \mathrm{H}_{2} \mathrm{O}, \mathrm{Co}-4 \mathrm{H}_{2} \mathrm{O}$, and $\mathrm{Co}$ in the range of -6 to $6 \mathrm{kOe}$; (c) $\mathrm{Ni}-10 \mathrm{H}_{2} \mathrm{O}, \mathrm{Ni}-4 \mathrm{H}_{2} \mathrm{O}$ and $\mathrm{Ni}$ in the range of -70 to $70 \mathrm{kOe}$.

are justified. One is that the spin states of the different moment carriers within the compounds remain unchanged upon transformation through the two dehydration processes. We can be certain that dehydration of the nickel compound does not form square planar $\mathrm{Ni}(\mathrm{II})$ geometry (Table 2) which will be diamagnetic. Whether it adopts a five or six coordination is not certain. We hypothesize that the first-step dehydration process could remove four lattice and two coordination water molecules, leading to the formation of $\mathbf{C o -}-\mathbf{4} \mathbf{H}_{2} \mathbf{O}$ with a layer structure and thus the inter-chain distance is significantly reduced (Fig. 1d). The clear two steps in the isothermal magnetization observed for $\mathbf{C o}-\mathbf{4} \mathrm{H}_{2} \mathrm{O}$ is a direct measure of the weak interactions between the chains within the layer that follows between layers. From the critical fields of the metamagnetism an estimate gives the interchain coupling averaging to $c a .0 .1 \mathrm{~K}$ and interlayer one of $c a .2 \mathrm{mK}$ (Fig. 6b). Such low coupling energies are what drives these very subtle metamagnetic transformations. Another parameter that can be confirmed is the enhancement of the antiferromagnetic exchange within and between the chains upon total dehydration, which leads to an enhanced ordering temperatures of the ferrimagnetic state in both cases. Interestingly, the rehydrated samples Co-RH and NiRH show almost the same magnetic behavior as those of the pristine ones (Fig. S9-S12 $\dagger$ ). The result indicates that both the structures and magnetic properties of $\mathbf{C o -}-\mathbf{1 0 H}_{2} \mathrm{O}$ and $\mathbf{N i - 1 0 H _ { 2 }} \mathrm{O}$ are reversible upon dehydration and rehydration.

\section{Conclusions}

We report two isostructural compounds, $\mathrm{M}_{3}{ }^{\mathrm{II}}(\mathrm{hpdpH})_{2}\left(\mathrm{H}_{2} \mathrm{O}\right)_{6}$ $\cdot 4 \mathrm{H}_{2} \mathrm{O}(\mathrm{M}=\mathrm{Co}$ and $\mathrm{Ni})$ based on a polytopic ligand $\mathrm{hpdpH}^{3-}$. They contain diamond chains of the metals bridged by O-P-O and connected to one another through $\mathrm{H}$-bonds involving $\mathrm{H}_{2} \mathrm{O} \cdots \mathrm{PO}_{3}$ and $\mathrm{H}_{2} \mathrm{O} \cdots \mathrm{NH}_{2}$ resulting in a 3D-net. The most significant feature is that both compounds undergo a consecutive two-step dehydration process, accompanied by dramatic changes in the magnetic properties - from paramagnet to antiferromagnet/metamagnet to ferrimagnet for $\mathbf{M}=$ Co and from antiferromagnet to antiferromagnet to ferrimagnet for $\mathrm{M}$ $=\mathrm{Ni}$. Such an interesting magnetic changes must be related to their structural transformations upon thermal treatment, possibly from chain $\left(\mathbf{M}-\mathbf{1 0} \mathbf{H}_{2} \mathbf{O}\right)$ to layer $\left(\mathbf{M}-\mathbf{4} \mathbf{H}_{2} \mathbf{O}\right)$ to more dense layer (M). Moreover, the dehydration/rehydration process is reversible with the recovery of both structures and magnetic behaviors. Further work is in progress to explore new metal phosphonates with their magnetic properties responsible to the external stimulus such as heat and light.

\section{Conflicts of interest}

There are no conflicts to declare.

\section{Acknowledgements}

Financial support by the National Key R\&D Program of China (2017YFA0303203, 2018YFA0306004) and the National Natural Science Foundation of China (21731003) are acknowledged. MK is funded by the CNRS, France.

\section{Notes and references}

1 (a) A. Clearfield, Progress in Inorganic Chemistry, Wiley, New York, 1998, vol. 47, pp. 371-510; (b) Metal Phosphonate Chemistry: From Synthesis to Applications, ed. A. Clearfield and K. Demadis, the Royal Society of Chemistry, 2012; (c) S. J. Shearan, N. Stock, F. Emmerling, J. Demel, P. A. Wright, K. D. Demadis, M. Vassaki, F. Costantino, R. Vivani, S. Sallard, I. R. Salcedo, A. Cabeza and M. Taddei, Crystals, 2019, 9, 270; (d) G. Yücesan, Y. Zorlu, M. Stricker and J. Beckmann, Coord. Chem. Rev., 2018, 369, 105-122; (e) A. D. G. Firmino, F. Figueira, J. P. C. Tomé, F. A. Almeida Paz and J. Rocha, Coord. Chem. Rev., 2018, 355, 133-149; (f) P. Bhanja, J. Na, T. Jing, J. Lin, T. Wakihara, A. Bhaumik and Y. Yamauchi, Chem. Mater., 2019, 31, 5343-5362; (g) J.-G. Mao, Coord. Chem. Rev., 2007, 251, 1493.

2 (a) B. S. Gelfand, R. P. S. Huynh, R. K. Mah and G. K. H. Shimizu, Angew. Chem., Int. Ed., 2016, 55, 1461414617; (b) T. Rhauderwiek, H. Zhao, P. Hirschle, M. Doblinger, B. Bueken, H. Reinsch, D. De Vos, S. Wuttke, 
U. Kolb and N. Stock, Chem. Sci., 2018, 9, 5467-5478; (c) H. Li, Y. Sun, Z.-Y. Yuan, Y.-P. Zhu and T.-Y. Ma, Angew. Chem., Int. Ed., 2018, 57, 3222-3227; (d) H. Tian, J.-B. Su, S.-S. Bao, M. Kurmoo, X.-D. Huang, Y.-Q. Zhang and L.-M. Zheng, Chem. Sci., 2018, 9, 6424-6433; (e) X. Chen, Y. Peng, X. Han, Y. Liu, X. Lin and Y. Cui, Nat. Commun., 2018, 8, 2171; (f) B. J. C. Wong, D.-m. Xu, S.-S. Bao, L.-M. Zheng and J. Lei, ACS Appl. Mater. Interfaces, 2019, 11, 12986-12992; $(g)$ E. Armakola, R. M. P. Colodrero, M. Bazaga-García, I. R. Salcedo, D. Choquesillo-Lazarte, A. Cabeza, M. V. Kirillova, A. M. Kirillov and K. D. Demadis, Inorg. Chem., 2018, 57, 10656-10666; $(h)$ T. Zeng, L. Wang, L. Feng, H. Xu, Q. Cheng and Z. Pan, Dalton Trans., 2019, 48, 523-534.

3 (a) S.-S. Bao and L.-M. Zheng, Coord. Chem. Rev., 2016, 319, 63-85; (b) S.-S. Bao, G. K. H. Shimizu and L.-M. Zheng, Coord. Chem. Rev., 2019, 378, 577-594.

4 E. Matczak-Jon and V. Videnova-Adrabińska, Coord. Chem. Rev., 2005, 249, 2458-2488.

5 L.-M. Zheng, H.-H. Song and X.-Q. Xin, Comments Inorg. Chem., 2000, 22, 129-149.

6 (a) K. Du, E. A. Waters and T. D. Harris, Chem. Sci., 2017, 8, 4424-4430; (b) F.-N. Shi, F. A. Almeida Paz, P. Ribeiro-Claro and J. Rocha, Chem. Commun., 2013, 49, 11668-11670; (c) F. Niekiel and N. Stock, Cryst. Growth Des., 2014, 14, 599606; (d) J.-H. Li, S.-D. Han, J. Pan, Z.-Z. Xue, G.-M. Wang, Z.-H. Wang and Z.-Z. Bao, CrystEngComm, 2017, 19, 11601164; (e) H.-H. Liu, Y.-J. Ma, S.-D. Han, J.-H. Li and G.-M. Wang, Dalton Trans., 2019, 48, 3955-3961.

7 (a) Z.-C. Zhang, S. Gao and L.-M. Zheng, Dalton Trans., 2007, 4681-4684; (b) T. Sun, C.-Q. Jiao, W.-Z. Li, Z.-G. Sun, C. Ma, Y.-Y. Zhu, M.-X. Ma, H. Luo, X.-W. Zhang and M.-L. Wang, RSC Adv., 2015, 5, 26410-26419.

8 (a) T. Rojek, W. Goldeman, K. Ślepokura, M. Duczmal, A. Wojciechowska and E. Matczak-Jon, Dalton Trans., 2017, 46, 6900-6911; (b) D.-K. Cao, M.-J. Liu, J. Huang, S.-S. Bao and L.-M. Zheng, Inorg. Chem., 2011, 50, 2278-2287; (c) D.-K. Cao, X.-J. Xie, Y.-Z. Li and L.-M. Zheng, Dalton Trans., 2008, 5008-5015; (d) T. Rojek, W. Goldeman, K. Ślepokura, W. Zierkiewicz and E. Matczak-Jon, CrystEngComm, 2019, 21, 4340-4353.

9 (a) R. Fu, S. Hu and X. Wu, Cryst. Growth Des., 2016, 16, 50745083; (b) Y.-H. Su, D.-K. Cao, Y. Duan, Y.-Z. Li and L.-M. Zheng, J. Solid State Chem., 2010, 183, 1588-1594; (c) Y. Ma, R. Yuan and L. Zheng, Inorg. Chem. Commun., 2009, 12, 860-863; (d) T. J. Greenfield, T. Takemoto, J. Cano, F. Lloret, M. Julve and J. Zubieta, Polyhedron, 2019, 169, 162-168.

10 (a) M. Nihei, Y. Yanai, I.-J. Hsu, Y. Sekine and H. Oshio, Angew. Chem., Int. Ed., 2017, 56, 591-594; (b) Z.-S. Yao, S.-Q. Wu, Y. Kitagawa, S.-Q. Su, Y.-G. Huang, G.-L. Li, Z.-H. Ni, H. Nojiri, Y. Shiota, K. Yoshizawa, S. Kang, S. Kanegawa and O. Sato, Angew. Chem., Int. Ed., 2017, 56, 717-721.
11 J.-X. Hu, L. Luo, X.-J. Lv, L. Liu, Q. Liu, Y.-K. Yang, C.-Y. Duan, Y. Luo and T. Liu, Angew. Chem., Int. Ed., 2017, 56, 7663-7668.

12 X. Ma, E. A. Suturina, S. De, P. Négrier, M. Rouzières, R. Clérac and P. Dechambenoit, Angew. Chem., Int. Ed., 2018, 57, 7841-7845.

13 (a) D. Shao, L. Shi, L. Yin, B.-L. Wang, Z.-X. Wang, Y.-Q. Zhang and X.-Y. Wang, Chem. Sci., 2018, 9, 79867991; (b) X.-N. Cheng, W.-X. Zhang, Y.-Y. Lin, Y.-Z. Zheng and X.-M. Chen, Adv. Mater., 2007, 19, 1494-1498; (c) S. I. Ohkoshi, K. I. Arai, Y. Sato and K. Hashimoto, Nat. Mater., 2004, 3, 857; (d) P. D. Diet-zel, Y. Morita, R. Blom and H. Fjellvåg, Angew. Chem., Int. Ed., 2005, 44, 63546358; (e) Z.-Y. Liu, E.-C. Yang, L.-L. Li and X.-J. Zhao, Dalton Trans., 2012, 41, 6827-6832.

14 (a) M. Kurmoo, Chem. Soc. Rev., 2009, 38, 1353-1379; (b) P. Dechambenoit and J. R. Long, Chem. Soc. Rev., 2011, 40, 3249-3265.

15 (a) T.-H. Yang, Y. Liao, L.-M. Zheng, R. E. Dinnebier, Y.-H. Su and J. Ma, Chem. Commun., 2009, 3023-3025; (b) J.-S. Feng, S.-S. Bao and M. Ren, Chem.-Eur. J., 2015, 21, 17336-17343.

16 S.-S. Bao, Y. Liao, Y.-H. Su, X. Liang, F.-C. Hu, Z. Sun, L.-M. Zheng, S. Wei, R. Alberto, Y.-Z. Li and J. Ma, Angew. Chem., Int. Ed., 2011, 50, 5504-5508.

17 Q. M. Gao, N. Guillou, M. Nogues, A. K. Cheetham and G. Ferey, Chem. Mater., 1999, 11, 2937-2947.

18 L. Widler, K. A. Jaeggi, M. Glatt, K. Müller, R. Bachmann, M. Bisping, A.-R. Born, R. Cortesi, G. Guiglia, H. Jeker, R. Klein, U. Ramseier, J. Schmid, G. Schreiber, Y. Seltenmeyer and J. R. Green, J. Med. Chem., 2002, 45, 3721-3738.

19 O. Kahn, Molecular Magnetism, VCH Publishers, Inc., New York, 1993.

20 SAINT, Program for Data Extraction and Reduction, Siemens Analytical X-ray Instruments, Madison, WI, 1994-1996.

21 G. M. Sheldrick, Acta Crystallogr., Sect. C: Struct. Chem., 2015, 71, 3-8.

22 Y.-H. Su, D.-K. Cao and L.-M. Zheng, Chin. J. Inorg. Chem., 2010, 26, 1617-1622.

23 R. A. Klemm and D. V. Efremov, Phys. Rev. B, 2008, 77, 184410-184433.

24 (a) H. Kumagai, C. J. Kepert and M. Kurmoo, Inorg. Chem., 2002, 41, 3410-3422; (b) M. Kurmoo, H. Kumagai, M. A. Green, B. W. Lovett, S. J. Blundell, A. Ardavan and J. Single-ton, J. Solid State Chem., 2001, 159, 343-351; (c) X.-J. Yang, S.-S. Bao, M. Ren, N. Hoshino, T. Akutagawa and L.-M. Zheng, Chem. Commun., 2014, 50, 3979-3981.

25 Y. Oka, K. Inoue, H. Kumagai and M. Kurmoo, Inorg. Chem., 2013, 52, 2142-2149.

26 (a) M. Kurmoo, H. Kumagai, K. W. Chapman and C. J. Kepert, Chem. Commun., 2005, 3012-3014; (b) L.-R. Guo, S.-S. Bao, B. Liu, D. Zeng, J. Zhao, J. Du and L.-M. Zheng, Chem.-Eur. J., 2012, 18, 9534-9542.

27 M. Kurmoo, H. Kumagai, M. Akita-Tanaka, K. Inoue and S. Takagi, Inorg. Chem., 2006, 45, 1627-1637. 